\title{
POLITICAS LINGUIISTICAS EM UMA ESCOLA PÚBLICA DE ENSINO MÉDIO E TECNOLÓGICO: A OFERTA DE LÍNGUAS ESTRANGEIRAS
}

\section{LANGUAGE POLICIES IN A PUBLIC TECHNICAL AND HIGH SCHOOL: THE OFFER OF FOREIGN LANGUAGES}

\author{
Glenda Heller Cáceres*
}

\section{RESUMO}

O presente artigo tem a finalidade de compreender a realidade da oferta de línguas estrangeiras em uma escola pública de Ensino Médio e Tecnológico do interior do Rio Grande do Sul. O estudo sustenta-se em referenciais teóricos atuais sobre políticas linguísticas, além de calcar-se em conceitos como governamentalidade e ideologia. A geração e análise dos dados se realizaram de acordo com uma perspectiva etnográfica, tomando-se como fonte entrevistas semi-estruturadas, registros visuais e análise documental. Os participantes são membros da instituição (uma ex-coordenadora de ensino e dois alunos) e seus relatos provêm elementos significativos para responder à pergunta de pesquisa, a saber: há indícios de que a visão ideológica dos alunos está em consonância com a política linguística da escola para as línguas estrangeiras no Ensino Médio? A apreciação dos dados permite-nos compreender que, embora pequenas mudanças estejam ocorrendo em termos político-linguísticos, elas não são suficientes para atender às expectativas dos alunos em relação às línguas estrangeiras ofertadas na escola.

Palavras-chave: políticas linguísticas; governamentalidade; ideologia; oferta de línguas estrangeiras.

\section{ABSTRACT}

This paper aims to understand the foreign languages' offer in a public technical and high school in the countryside of Rio Grande do Sul. The study presented here is based on current theoretical references about language policy and it is supported by the concepts of governmentality and ideology. Data generation and analysis were made according to ethnographic perspective, taking as source semi-structured interviews, document analysis and visual records. The participants are members of the institution (one ex-coordinator and two students). Their reports gave us significant elements to answer our research question, which is: is there evidence that the students' ideological view is in consonance with the school's linguistic policy to foreign languages in high school? The data analysis allows us to understand that small changes related to language policy are in course, however they are

\footnotetext{
* Instituto Federal de Educação, Ciência e Tecnologia do Rio Grande do Sul (IFRS). Porto Alegre (RS), Brasili cáceres_gle@hotmail.com
} 
not enough to answer the students' expectations related to the foreign languages offered in the school.

Keywords: language policies; governmentality; ideology; foreign languages' offer.

\section{INTRODUÇÃO}

Este artigo busca compreender as perspectivas dos alunos sobre a oferta de línguas estrangeiras ${ }^{1}$ em uma escola pública de Ensino Médio e Tecnológico, levando-se em consideração os documentos que regulam essa oferta na instituição e as condutas dos gestores para tomar decisões a respeito dessas línguas.

Esta investigação é relevante não apenas para os professores e gestores da escola, dado que os achados permitirão uma reflexão sobre a oferta de línguas estrangeiras segundo os anseios dos alunos, mas, principalmente, para levantar uma discussão sobre políticas linguísticas na esfera institucional escolar. Entre condutas top down e bottom u² $^{2}$, as políticas linguísticas encontradas neste trabalho são, possivelmente, comuns a outros tantos cenários escolares brasileiros.

No que diz respeito ao debate sobre questões político-linguísticas, algumas das obras que as apresentam (RICENTO, 2006; MENKEN e GARCÍA, 2010; MCCARTY, 2011) parecem estar voltadas especialmente a três eixos de pesquisa: a convivência entre línguas majoritárias e línguas minoritárias (línguas indígenas, línguas de imigração e, em poucos casos, língua de sinais); o contato linguístico determinado por questões geográficas (em especial, as línguas de fronteira); e a relação entre essas línguas e o contexto escolar.

Tais eixos não demonstram, necessariamente, limites claros entre si. Pode-se dizer, inclusive, que compartilham uma característica: estão alocados em ecologias bilíngues. No caso da pesquisa aqui apresentada, a realidade que descrevemos é a de uma escola sem orientação para o bilinguismo ${ }^{3}$. Apesar de evidente no contexto

1 Dá-se preferência para o termo 'línguas estrangeiras' em virtude de seu uso nos documentos considerados neste artigo, ao invés de 'língua adicional'(termo frequentemente usado em estudos de educação linguística e/ou ensino-aprendizagem de línguas) ou 'língua de herança' (termo empregado na área de política linguística, em especial nos estudos relativos a línguas indígenas, coloniais ou de imigração).

2 Políticas linguísticas top down têm sido entendidas como aquelas decisões sobre as línguas, tomadas por pessoas de poder e autoridade, em geral sem consulta aos aprendizes ou usuários dessa língua (KAPLAN e BALDAUF, 1997). Já as políticas bottom up seriam aquelas em que os próprios usuários tomam decisões sobre sua língua.

3 Não é do escopo deste trabalho discutir as noções de bilinguismo. No nosso caso, chamamos bilinguismo (ou bilinguismo social) à situação de convivência de, ao menos, duas línguas - em especial, português e italiano - no linguajar diário da comunidade onde a escola está inserida. A não promoção do bilinguismo, aqui, significa não contemplar as línguas de prática da sociedade dentro do ambiente formal escolar. 
social (a instituição está situada em uma zona de grande contingente populacional de descendentes de etnias europeias), o bilinguismo não é considerado na elaboração dos documentos que determinam as línguas estrangeiras a serem oferecidas na escola e que orientam as práticas com essas línguas em sala de aula.

Essa realidade - em que as escolhas, na escola, supostamente são tomadas a partir de ideologias linguísticas do mundo contemporâneo (motivo pelo qual, juntamente com o inglês, é obrigatório o ensino de espanhol), sem a promoção de práticas ligadas ao bilinguismo social (português e italiano/alemão) - parece dispor de uma quantidade pouco significativa de estudos publicados na área de políticas linguísticas. Nas obras consultadas que apresentam preocupação empírica, e não só teórica, com as políticas linguísticas (MCCARTY, 2011; MENKEN e GARCÍA, 2010), nas quais há exemplos em que tais políticas são extensivamente descritas, examinam-se casos em que o objetivo é, justamente, promover o bilinguismo social nas ações escolares.

Esse elemento lacunar, a saber, a política linguística em contextos escolares sem orientação para a promoção do bilinguismo social, será tratado em relação às línguas ofertadas na grade curricular regular da escola investigada, já que a sala de aula é o único momento dedicado à aprendizagem dessas línguas. Para tal, serão consideradas as ideologias que subjazem a essa oferta, tanto nas escolhas institucionais, quanto na perspectiva dos alunos. Também serão tratadas as relações de poder implicadas nas decisões sobre essa oferta.

Desse modo, o capítulo que segue trata de elucidar alguns conceitos que fundamentam a análise dos dados. Em seguida, são explicitados os procedimentos metodológicos adotados e reveladas as análises. Finalmente, são apresentadas considerações acerca da realidade investigada, propondo-se alguns encaminhamentos para o tratamento da oferta de línguas na escola em questão.

\section{REFLEXÕES TEÓRICAS}

A escolha das línguas a serem ensinadas a um público determinado é tema de interesse na área investigativa das políticas linguísticas. Claro está que essa eleição não é espontânea, mas sim feita por aqueles que têm capacidade para efetivá-la. Assim, a agentividade, sob o ângulo da política linguística, pode ser desempenhada tanto pelas pessoas em seu fazer linguístico cotidiano, quanto pelos representantes do governo, em caráter oficial (RICENTO, 2006), ou ainda pelos próprios professores, nas suas tarefas escolares (MENKEN e GARCÍA, 2010). 
$\mathrm{Na}$ ecologia linguística, esses agentes não são entidades isoladas, o que quer dizer que atuam simultaneamente, compartilhando espaços sociais. Segundo Tollefson (2006), em todas as relações sociais está implícita a força do poder e este vem a ser, portanto, outro ponto crucial na investigação político-linguística. Nesse ínterim, o papel do governo do Estado parece ser o mais facilmente observável, apesar de não ser o único, no processo decisório sobre as línguas. Acerca dos diferentes procedimentos usados na atuação do governo ${ }^{4}$, Pennycook (2006, p. 65) revela que

A governamentalidade linguística pode [portanto] ser entendida em termos de como as decisões sobre as línguas e as formas linguísticas através de um conjunto diverso de instituições (direito, educação, medicina, artes gráficas) e através de um conjunto diverso de instrumentos (livros, regulamentos, exames, artigos, correções) regulam o uso da língua, o pensamento e as ações de diferentes pessoas, grupos e organizações.

Para Menken e García (2010), uma abordagem ecológica das políticas linguísticas educacionais no século XXI deve estar atenta às dinâmicas dessas políticas, observando que assim como há aquelas que emergem das autoridades em direção à base, também há as que partem da base (usuários das línguas, entre os quais estão incluídos estudantes, professores e gestores educacionais) em direção ao topo, tais como as interpretações e as ações sobre essas políticas, por exemplo.

A instituição escolar, nesse vai-e-vem das dinâmicas políticas, parece ocupar uma posição intermediária, com função mediadora entre topo e base. Por isso, a ideologia subjacente à escolha das línguas oferecidas no ambiente escolar e as práticas de seus protagonistas tornam-se especialmente intrigantes e revelam-se como focos desta pesquisa acadêmica. Para elucidá-las, antes vamos propor uma breve reflexão sobre os termos 'ideologia linguística' e 'governamentalidade'.

\subsection{Ideologia linguística}

Do ponto de vista da Antropologia Social, de acordo com Kroskrity (2004), a ideologia linguística não é um conceito único, mas um conjunto de conceitos

\footnotetext{
4 A noção de governo empregada aqui é a de modos de atuação, de realização de atividades. Essa é a noção atribuída ao conceito de governamentalidade na citação de Pennycook (2006, p. 65). Porém, em alguns casos, trataremos do governo do Estado, assim referido, quando a intenção for a de atribuir ao Estado (como um sistema formal de instituições, cf. Blommaert, 2006) a forma mediante a qual é regido.

5 Language governmentality can [therefore] be understood in terms of how decisions about languages and language forms across a diverse range of institutions (law, education, medicine, printing) and through a diverse range of instruments (books, regulations, exams, articles, corrections) regulate the language use, thought, and action of different people, groups and organizations. (Tradução minha)
} 
convergentes que, apesar de parcialmente sobrepostos, diferem analiticamente. A partir dessa colocação, o autor distingue cinco níveis de significação para o termo 'ideologia linguística', dentre os quais três são considerados crenças, enquanto que os outros dois são utilizados a fim de ajudar no estudo dessas crenças.

Antes de tratar dos referidos níveis propostos pelo autor, cabe elucidar as entrelinhas de suas palavras. Assim, considerá-los analiticamente diferentes implica em um exame minucioso que permita observar em quais aspectos cada um dos significados é singular. Porém, esses significados contêm, também, aspectos comuns. São as 'camadas sobrepostas', na linguagem do autor. Portanto, de alguma maneira, os vários conceitos para um único termo convergem a um ponto central que perpassa qualquer um deles: entender a ideologia linguística como as crenças sobre a língua, sejam elas manifestadas explicitamente ou compartilhadas tacitamente.

Trataremos, em seguida, de cada um desses níveis, buscando descrevê-los brevemente. Lembramos que, entre eles, os três primeiros a serem apresentados constituem o que o autor chama de significados, propriamente ditos. Os dois subsequentes são considerados funções ideológicas, mais que significados do termo 'ideologia'. Por fim, tentaremos elucidar o que todos eles possuem em comum, já que se trata de 'camadas sobrepostas' dessa significação.

Entre os significados dados à ideologia linguística, Kroskrity (2004) destaca aquele que representa a concepção de língua construída de acordo com os interesses de um grupo (cultural ou social) específico. Nessa concepção, aquilo que adjetiva uma língua é gerado na experiência social e mostra-se, frequentemente, ligado a interesses político-econômicos. Nesse caso, rejeita-se a existência de falantes de uma língua que sejam social ou politicamente desinteressados. Programas nacionalistas de estandardização linguística ${ }^{6}$ são exemplos típicos desse nível ideológico.

A ideologia linguística (KROSKRITY, 2004) é proveitosamente concebida como múltipla e isso constitui mais um de seus significados. A multiplicidade reside na pluralidade de segmentos sociais, os quais permitem gerar perspectivas diferentes, que são índices do pertencimento a um grupo específico (gênero, classe social, geração, etc.). Outro nível de significação da expressão ideológica está vinculado ao grau de consciência dos falantes sobre as ideologias linguísticas

6 Na sistematização elaborada por Hornberger (2006), existem dois processos de estandardização. Um deles, referente ao planejamento de status da língua, ocupa-se de impor ou aceitar uma língua como padrão. O outro diz respeito ao planejamento de corpus, no qual as atividades consistem em codificar as formas linguísticas do padrão como uma norma uniforme. 
locais. Kroskrity (2004) indica que essa consciência pode ser apenas prática (ou tácita), sobre a qual os falantes não fazem discussão, já que é relativamente automatizada ${ }^{7}$.

Kroskrity (2004) também distingue algumas funções da ideologia linguística. Entre elas há uma que consiste em mediar as estruturas sociais e as formas de fala. Para Kroskrity (2004, p. 508), as "ideias sobre a língua emergem da experiência social e influenciam profundamente a percepção das formas linguísticas e discursivas". Outra das funções ideológicas é a de fundar e representar identidades culturais e sociais. Conforme o autor, a língua tem sido um dos critérios usados para naturalizar um grupo social, classificando-o como nacional ou étnico, por exemplo. Uma representação identitária pode, então, ser uma representação ideológico-linguística.

Apesar de apresentar cinco níveis para a ideologia linguística, as palavras de Kroskrity (2004) nos possibilitam evidenciar que em qualquer um deles a ideologia se constitui, fundamentalmente, das crenças - na sua forma mais consciente - e dos sentimentos - em sua manifestação menos reflexiva - sobre as línguas, tal como estas são usadas no mundo:

Certamente as ideologias linguísticas não são meramente aquelas ideias que partem da "cultura oficial" da classe dominante, mas muito mais presentes como um conjunto de crenças diversas, independentemente de serem implícitas ou explícitas, usadas pelos falantes de todos os tipos como modelos para a construção de avaliações linguísticas e para o engajamento em atividades comunicativas (KROSKRITY, 2004, p. 497) . $^{8}$

Já Woolard (1992), aponta quatro dimensões comuns para o termo ideologia, o qual também apresenta variações. A partir de uma perspectiva semelhante à de Kroskrity (2004), a primeira das características centrais do termo, conforme a autora, é aquela que o toma como conceitual ou ideal, relacionando-o às crenças, noções, ideias e à consciência. A ideologia, aqui, permanece no plano intelectual. A segunda, igualmente próxima à do autor mencionado anteriormente, é aquela em que os conceitos ou as noções ideológicas são vistos como um reflexo de (e a autora acrescenta: 'derivados das', 'baseados nas' e 'sensíveis às') experiências e interesses

7 Kroskrity (2004), seguindo a Giddens (1984), entende a ideologia prática como uma conduta quase automática sobre as questões ideológicas já incorporadas nos falantes, porém nunca ditas e a ideologia discursiva como uma forma de reflexão monitorada que permite aos falantes discutir explicitamente questões de ideologia linguística.

8 Certainly language ideologies are not merely those ideas which stem from the "official culture" of the ruling class but rather a more ubiquitous set of diverse beliefs, however implicit or explicit they may be, used by speakers of all types as models for constructing linguistic evaluations and engaging in communicative activity. (Tradução minha; grifo meu) 
de uma posição social particular. Woolard (1992) ressalta que, embora a ideologia reflita concepções de um grupo, é apresentada como se fosse uma verdade universal.

A terceira e quarta interpretações não encontram paridade com as definições de Kroskrity (2004). Uma delas trata a ideologia como uma noção de distorção, de falsidade, de mistificação; a outra liga ideologia a poder social e legitimação (WOOLARD, 1992). Numa interpretação efusiva dessa última perspectiva, a ideologia é sempre considerada como uma ferramenta ou propriedade dos grupos sociais dominantes e, nesse sentido, diferencia-se da segunda dimensão terminológica atribuída pela autora. Os grupos de menor poder são considerados não ideológicos diante desta última perspectiva.

No que concerne às variações entre as definições de ideologia, Woolard (1992) destaca dois aspectos: entendê-la como um sistema coerente e concebê-la como uma expressão explícita da consciência. Nesse sentido, a autora difere de Kroskrity (2004), que indica que a consciência dos falantes é apenas um dos níveis de significação linguístico-ideológico, conforme explicitado anteriormente.

Buscando encontrar uma concepção que sirva para os propósitos deste trabalho, não focamos na singularidade, mas no que há de comum em torno do significado de ideologia linguística. Portanto, propomos o seguinte diagrama, que mostra os aspectos salientados por cada um dos autores em questão, assim como as características ideológicas compartilhadas por eles (círculo central, Figura 1).

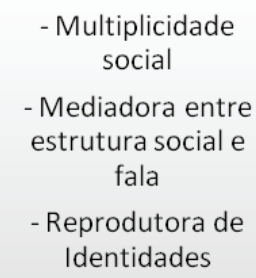

- Multiplicidade

- Mediadora entre estrutura social e fala Identidades

Figura 1. Significados para ideologia linguística, baseados em Kroskrity (2004) e Woolard (1992)

Considerando as observações feitas, adotaremos o termo 'ideologia linguística' como a expressão, explícita ou implícita, das concepções de um grupo sobre as línguas, tomando a ideia de Kroskrity (2004) de que tais concepções ou crenças são construídas também para avaliar essas línguas. 
Uma vez que as concepções em que estamos interessados são aquelas compreendidas no âmbito escolar por seus atores, entendemos que devemos buscar saber como se conformam. Para tanto, conforme explicitado nos parágrafos introdutórios desta seção teórica, observaremos o caráter governamental que pode influenciar e ser influenciado por essas concepções. O tópico seguinte elucidará esta questão.

\subsection{Governamentalidade}

Diante da necessidade de organizar as tarefas que competem à escola, como instituição pública, e, consequentemente, aos professores, existe uma variedade de documentos. Tais documentos (produzidos na própria escola ou originários do governo do Estado) visam a indicar ou regulamentar as condutas no âmbito institucional.

Acerca dessa organização, trabalhos acadêmicos da área de políticas linguísticas ${ }^{9}$ têm usado o termo governamentalidade, cunhado por Foucault, uma vez que a expressão é considerada uma ferramenta útil de análise para a sociedade moderna. Nesse arranjo social, existe uma questão central que é a de conduzir, entre outras instâncias, a sociedade, seus indivíduos e o próprio Estado (AMOS, 2010). E é justamente o vocábulo "conduzir", o que sintetiza a noção advinda do termo governamentalidade. No dicionário eletrônico Houaiss (2001), existem dezessete entradas para a palavra "conduzir". Mas de todos os significados, vamos destacar aquele que primeiro aparece entre as acepções dadas: "ir junto com ou dentro de (algo), de um lugar para outro, dando-lhe direção e/ou comando; guiar, dirigir".

É importante destacar que o termo governamentalidade, entendido como 'gestão governamental' ou 'práticas de governo' (MACHADO, 2009, p. XXIII), surge em um momento histórico em que se contrapõe a um comando soberano - como aquele que um príncipe exerce sobre o seu principado - um governo voltado à população. Historicamente, a mudança em direção à "arte de governar" (FOUCAULT, 1979/2009), isto é, à governamentalidade, começa quando o chamado Estado de Justiça (Feudalismo; Idade Média) - no qual a sociedade é regida pela lei, dispondo de técnicas de punição específicas no caso de transgredi-las - passa a ser um Estado Administrativo (séculos XV e XVI).

No Estado Administrativo, da monarquia territorial, é a disciplina o grande dispositivo do poder. Desenvolvida em instituições como escolas, exércitos e

\footnotetext{
9 Exemplos disso são os capítulos de Tollefson e Pennycook, publicados na obra organizada por Ricen-
} to (2006), ou ainda o capítulo de Ramanathan, na obra organizada por McCarty (2011). 
oficinas, a disciplina tem a vigilância como um de seus principais instrumentos de controle. Nesse período, a soberania e o Estado, de um lado, encontravam sua contraparte na família e seu gestor. A família era, então, o foco de incidência do poder soberano. Já no século XVIII, o Estado Administrativo transforma-se em Estado de Governo, no qual é a população seu foco principal, não mais a família. Esta vem a ser apenas um segmento daquela e é usada como instrumento para atingi-la. (FOUCAULT, 1979/2009; VEIGA-NETO e LOPES, 2007).

Diante disso, vejamos nas palavras de Foucault (1979/2009; p. 291-292) aquilo que relata querer significar com o termo governamentalidade.

Com esta palavra quero dizer três coisas:

1 - o conjunto constituído pelas instituições, procedimentos, análises e reflexões, cálculos e táticas que permitem exercer essa forma bastante específica e complexa de poder, que tem por alvo a população, por forma principal de saber a economia política e por instrumentos técnicos essenciais aos dispositivos de segurança.

2 - a tendência que em todo o Ocidente conduziu incessantemente, durante muito tempo, à preeminência deste tipo de poder, que se pode chamar de governo, sobre todos os outros - soberania, disciplina, etc. - e levou ao desenvolvimento de uma série de aparelhos específicos do governo e de um conjunto de saberes.

3 - o resultado do processo através do qual o Estado de justiça da Idade Média, que se tornou nos séculos XV e XVI Estado administrativo, foi pouco a pouco governamentalizado.

A partir do exposto e daquilo que encontramos na obra de Foucault (1979/2009), podemos sintetizar as seguintes mudanças que levaram à "arte de governar":

a. foco do Estado na população, e não mais na família;

b. mudança de um comando soberano para uma ciência do governo, que deve observar a população para que possa ser efetiva;

c. surgimento da economia política como técnica de intervenção do governo no setor econômico, e não mais na riqueza familiar.

Assim, em nossa leitura sobre o capítulo foucaultiano da governamentalidade, a palavra "governo" passa a designar táticas de poder exercidas por aqueles que governam através de intervenções na população para atingir fins específicos. Cabe ressaltar, ainda, que nos escritos de Foucault (1979/2009) admite-se que muitas pessoas podem governar, não apenas os representantes do Estado, uma vez que existem práticas múltiplas de governo. No entanto, em sentido mais estrito, é o 
governo do Estado que objetiva organizar a conduta da população em nossa sociedade; que exerce o poder.

De qualquer modo, segundo vimos observando, os sentidos de governar e conduzir, muito próximos nesse contexto, permitem-nos entender que em qualquer um deles demonstra-se uma relação entre os que estão e os que não estão desempenhando esse poder (ou seja, aquele que guia e aquele que é guiado; aquele que conduz e aquele que é conduzido, etc.).

Se ao Estado cabe, então, dirigir a sociedade, bem como as instituições e indivíduos que a conformam, a escola, como representante dessas instituições, também se encontra sob o seu poderio. Destarte, o Estado encontra na escola uma de suas ferramentas de direcionamento das ações dos indivíduos da sociedade moderna. Sobre isso, e a respeito das políticas de inclusão, Veiga-Neto e Lopes (2007, p. 957-958) afirmam que a escola "funcionou - e continua funcionando - como o lugar privilegiado para a invenção e experimentação dos novos saberes e para a intervenção do Estado e de suas políticas [...]".

Fazem parte das políticas do Estado, e dos interesses deste trabalho, as políticas linguísticas. Entendemos que

Política linguística sempre foi muito mais que a escolha de quais línguas usar no governo, na educação, ou na lei, que tomar decisões sobre o meio de instrução nas escolas ou o papel dos tradutores nas cortes e governos, ou a implementação de resoluções justas de política estatal. Política linguística tem a ver com o uso das línguas como parte da governamentalidade linguística (PENNYCOOK, 2006, p. 64). ${ }^{10}$

Com isso, Pennycook parece dizer que as decisões tomadas a respeito do uso da língua regulam não somente a língua per se, mas o pensamento e as ações de uma população sobre a língua. Assim sendo, não só a escolha feita pela(s) língua(s) ensinada(s) na escola, mas o que se faz com elas e o que se pensa delas, são, da mesma forma, expressões dos mecanismos dirigentes dos discursos e das práticas de governo: a governamentalidade.

Pennycook (2006) menciona, ainda, que a ideia de governamentalidade não pode ser entendida como atuações de governo realizadas conforme uma 'vontade própria'. É necessário notar que há diversas operações de poder que ocorrem na prática de comando do governo. Não se trata apenas de normas prescritivas a serem se-

10 Language policy has always been about far more than choosing which language to use in government, education, or the law, making decisions about the medium of instruction in schools or the role of translators in courts and governments, or implementing rational state policy resolutions. Language policy has to do with the use of languages as part of language governmentality. (Tradução minha; grifo no original) 
guidas. São, na verdade, também as práticas já operantes, a língua que está em uso, os discursos em circulação. Contudo, aquilo que, por um lado, pode ser entendido como uma política de oferta de língua estrangeira na escola, para proporcionar aos alunos conhecimento linguístico e cultural ligados a essa língua, por outro lado, pode esconder uma face diversa da governamentalidade. Nesse caso, trata-se de uma maneira dissimulada de guiar a população (os membros componentes da instituição escolar), em que o governo do Estado a manipula em favor próprio.

Para aproximar esse construto teórico de nossa realidade, podemos pensar na Lei 11161/2005, que instituiu a obrigatoriedade da oferta de língua espanhola nas escolas de Ensino Médio no Brasil, além de acordos realizados entre o governo brasileiro e o espanhol - que vão desde a abertura a instituições privadas, como o Instituto Cervantes, para exercer atividades educativas primariamente destinadas aos profissionais brasileiros com formação acadêmica na área, até a implantação de bancos, como o Santander, que goza de um grande poder econômico na nossa sociedade. Na época em que a lei foi sancionada, veiculou-se na mídia que o governo brasileiro estaria pagando parte de suas dívidas à Espanha e, em troca, treinadores de língua espanhola viriam ao Brasil 'formar' os professores de língua daqui (ROSSI, 2005). Esse ato político, linguístico e governamental suscitou inúmeros debates entre esses professores no Brasil ${ }^{11}$.

Dito isso, é chegado o momento de investigar como a governamentalidade incide na conduta em relação às decisões sobre as línguas estrangeiras oferecidas na instituição em foco, nas imposições à e da escola. Explicaremos, na seção que se segue, os procedimentos de pesquisa adotados para esse fim.

\section{PROCEDIMENTOS METODOLÓGICOS}

Esta pesquisa emerge, como já foi dito, do interesse em entender como os alunos do Ensino Médio percebem as políticas de oferta de línguas estrangeiras na instituição investigada: uma escola pública federal. Tal interesse surgiu em face da minha atuação como professora nesse contexto, o qual pude observar (e vivenciar) por aproximadamente dois anos até a conclusão deste estudo. As conversas informais que desenvolvemos na instituição constituíram nosso espírito investigativo e geraram a seguinte pergunta de pesquisa: há indícios de que a visão ideológica

11 A partir do convênio entre o governo brasileiro e o Instituto Cervantes instauraram-se vários atos de repúdio dos professores, alguns deles publicados no seguinte site, fundado a partir da validação da referida lei: http://espanholdobrasil.wordpress.com/ 
dos alunos está em consonância com a política linguística da escola para as línguas estrangeiras no Ensino Médio?

Para responder à pergunta de pesquisa, fundamentamos a geração e a análise dos dados nas premissas etnográficas. Conforme Mattos (2001), uma pesquisa etnográfica é guiada pelo senso questionador do pesquisador, o qual se valerá da observação direta das práticas diárias das pessoas de uma comunidade - neste caso, dos membros da escola - por um período de tempo tal que se possa chegar próximo ao significado que essas pessoas atribuem ao que ocorre nessa comunidade.

A fim de aproximar-se dessa perspectiva, o etnógrafo faz observações dentro da comunidade investigada, complementando-as com entrevistas, notas de campo ou outros elementos, de modo que se possa fazer um cruzamento das informações (CANAGARAJAH, 2006). Assim, nossa experiência como professora da escola permitiu a análise não só das interações imediatas advindas das conversas informais com os alunos e das entrevistas realizadas para esta pesquisa, mas, da mesma forma, disponibilizou a compreensão dessas interações na amplitude do contexto escolar em foco.

Embora o tempo de imersão e de observação direta na escola investigada não possam ser classificados neste estudo como dados etnográficos, uma vez que não foram feitos sistemática e analiticamente com vistas à realização deste trabalho, foram fundamentais em seu papel de incitadores das perguntas e expectativas que levaram a conduzir a pesquisa. Assim, consideramos como dados de pesquisa etnográfica neste estudo as análises documentais dos PPC (Projeto Pedagógico de Curso) do Ensino Médio, os registros visuais da escola e da sociedade em que está inserida e, ainda, as entrevistas com três participantes: uma ex-coordenadora do Ensino Médio e dois alunos desse nível escolar, cada um pertencente a um dos cursos técnicos oferecidos na instituição para a modalidade integrada (Agropecuária e Informática para a Internet).

Além da descrição dos PPC, outros documentos, da esfera federal, foram também revisados (PCN-EM, 1999/2000; LDB, 1996/2010) para amparar a análise das entrevistas. Estas, por sua vez, foram feitas em uma pequena sala de reuniões de professores, disponibilizada, nos momentos dessa tarefa, unicamente para esse fim. As três entrevistas aconteceram em janeiro de 2013, nos dias 04, 07 e 17, no turno da tarde. Foi a professora-pesquisadora, autora deste trabalho, quem se pôs em contato com os participantes e, mediante o seu consentimento, conduziu as entrevistas. As entrevistas semi-estruturadas ${ }^{12}$ continham tópicos aos quais estavam

12 Entrevista semi-estruturada é aquela "que se baseia em questões específicas, porém sem ordenamento rígido" (LUDWIG, 2009, p. 66). 
circunscritas as perguntas que foram respondidas pelos três participantes (com a inclusão de algumas indagações surgidas da necessidade de maiores esclarecimentos). As entrevistas duraram, em média, 10 minutos cada.

Os dados gerados nas entrevistas foram transcritos integralmente ${ }^{13}$. Em seguida, buscamos encontrar os trechos que seriam representativos dos olhares dos participantes sobre as políticas de oferta de línguas na escola. Linguisticamente, foram tomados como índices de seleção: a) menções explícitas às onomásticas das línguas; b) referências pronominais, como 'nós'/'a gente', sugerindo coletividade, e 'eu'/'minha', por exemplo, sugerindo individualidade; c) palavras indicativas de governamentalidade, também nos níveis coletivo e individual (por exemplo: governo, lei, decidir, escolher, etc.), e d) expressões de sentido valorativo (por exemplo: irrelevante, importante, etc.). A análise dos dados originada desses elementos indicativos será apresentada a seguir.

\section{ENTRE GOVERNAMENTALIDADE E IDEOLOGIAS}

\subsection{A escola e os documentos reguladores}

A escola em que se ambienta esta pesquisa faz parte de um grupo de instituições federais e está localizada no interior do Rio Grande do Sul. Nela são oferecidos cursos de vários níveis e de diferentes modalidades. Neste contexto de pesquisa, focamos no nível de Ensino Médio, em uma das modalidades de curso existentes, a de Técnico Integrado ${ }^{14}$, nos Cursos de Agropecuária (AP) e de Informática para Internet (II).

O número total de alunos no Ensino Médio gira em torno de 300 (dados de dezembro de 2012), sendo que $75 \%$ deles são estudantes de AP e II. Os PPCs ${ }^{15}$ dos cursos em análise nesta pesquisa são de 2008, o de II, e de 2009, o de AP. O PPC é o único documento produzido na instituição que regulariza o ensino de línguas estrangeiras.

Tanto o curso de II, que finda ao término de quatro anos de estudo, quanto o curso de AP (de três anos) têm determinação expressa no PPC quanto ao nú-

\footnotetext{
13 As entrevistas foram transcritas em português padrão, com a maior fidelidade possível à fala dos participantes. O sinal "(...)" indica supressão de texto, as reticências sinalizam pausas prosódicas e os colchetes introduzem informações contextuais que não aparecem no excerto.

14 Como o próprio nome sugere, os cursos ditos Integrados possuem um único plano de curso na tentativa de associar as disciplinas do ensino técnico às do Ensino Médio.

15 Atendendo aos princípios éticos da pesquisa, as fontes dos PPCs não são citadas nas Referências Bibliográficas, pois permitiriam desvelar o caráter sigiloso da instituição investigada.
} 
mero de horas totais de aula, distribuição das horas ao longo do curso e conteúdo programático (que estabelece os objetivos e os conteúdos linguísticos a serem desenvolvidos em cada ano, além de conter as referências bibliográficas da disciplina). As línguas espanhola e inglesa (as únicas línguas estrangeiras oferecidas na escola) devem ter 160 horas-aula, distribuídas em dois anos letivos, com dois períodos semanais cada uma.

No PPC de $\mathrm{AP}^{16}$ faz-se menção específica à Lei 11161, de agosto de 2005, que trata da obrigatoriedade da oferta da língua espanhola nas escolas públicas de Ensino Médio. Menciona-se no documento que devido à Lei 11161 o ensino de espanhol passa a formar parte da grade regular, pois é obrigatório. Contudo, a interpretação dada à Lei parece equivocada, já que, como apontam alguns autores (RODRIGUES, 2010; GONZÁLEZ, 2010), a oferta é, sim, obrigatória, mas o modo como se aplicará na escola (grade curricular, cursos de extensão, etc.), é de escolha da própria instituição. Se não se trata de um equívoco, podemos inferir que a aplicação dada pela escola a essa Lei é uma maneira intencionada de conduzir as práticas que se produzem ali, quer dizer, é um exemplo da governamentalidade em nível escolar.

Ao longo de dois anos na instituição, a pesquisadora dialogou diversas vezes com seus alunos sobre as línguas oferecidas pela escola e sobre a forma como estão distribuídas durante os anos de curso (na Figura 2, a Cooperativa Escola, lugar onde ocorreu a maior parte das conversas informais com os alunos). A partir de então, muitas questões surgiram, especialmente sobre o planejamento linguístico e as mudanças sociais que este pode acarretar. Para compreender o cenário linguístico circundante, foram entrevistados três membros escolares. A seguir, apresentamos e interpretamos alguns excertos dos diálogos gerados.

16 O PPC de AP foi atualizado em 2011, porém não foi o que regulamentou o período de escolaridade dos participantes entrevistados para fins deste trabalho e, por esse motivo, foi analisada a versão anterior do documento. A única alteração, em termos de línguas, foi o aumento da carga-horária de inglês, que passou de 160 para 200 horas-aula. 


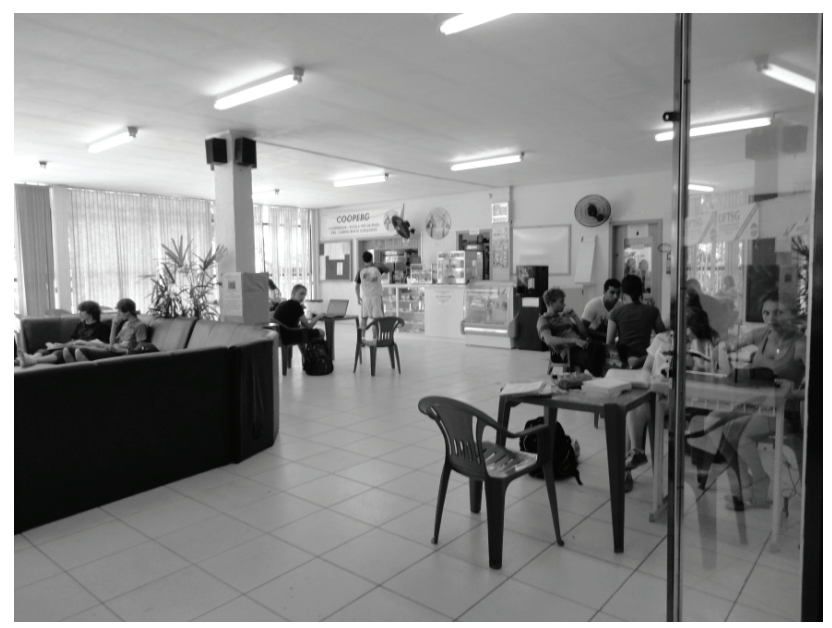

Figura 2. Cooperativa Escola

\section{2. "A gente" é muitos, né? - o pano de fundo da política para as lín- guas estrangeiras na escola}

Segundo mencionamos, um dos entrevistados é uma antiga coordenadora de ensino, Rosa ${ }^{17}$, que atuou no gerenciamento de questões político-pedagógicas na maior parte do tempo em que os alunos-participantes frequentaram a escola. Essa foi a razão que levou à seleção da ex-coordenadora como participante desta pesquisa.

Segundo Rosa, numa época mais remota, a única língua oferecida na escola era o inglês. Porém, posteriormente, reconheceu-se a língua espanhola como um recurso igualmente importante para a formação dos alunos. Sendo assim, optou-se por incluí-la na grade curricular da escola. $\mathrm{O}$ excerto a seguir ilustra essa percepção:

No início era só o inglês como língua. E aí, a partir de um certo momento aonde a gente percebeu da importância também do espanhol, não só nós como toda a conjuntura, né? Se percebeu da importância da língua espanhola (...) Mas no sentido de uma formação, uma melhor capacitação a nível de línguas. (Excerto de entrevista - 17.01.2013)

No decorrer da conversa, a pesquisadora perguntou a quem a ex-coordenadora fazia referência ao utilizar "a gente", "nós" ou "toda a conjuntura". E ela esclareceu:

17 A fim de preservar a identidade dos entrevistados, os nomes que constam neste trabalho são fictícios e foram escolhidos pelos próprios participantes. 
"A gente" é muitos, né? A gente é governo, a gente é instituto, departamento, né? Então a gente é... é vários. Eu acho que a escola aqui sempre foi muito aberta nesse sentido de oferecer sempre as duas línguas, né? (...) aqui foi sempre bem vista... o trabalho com as duas línguas, apesar de até então, o espanhol não ser uma língua obrigatória por lei, né, a ser oferecida nos currículos. (Excerto de entrevista - 17.01.2013)

De suas palavras é possível inferir que a política linguística exercida na escola depende de um conjunto de atores. Tais atores atuam, simultaneamente, no nível institucional ('a gente' como instituto ou departamento) e no nível nacional ('a gente' como governo do Estado). Também podemos dizer que a decisão da escola por implantar a língua espanhola na grade curricular foi anterior à Lei 11161/2005 e esse foi o padrão seguido pala instituição por vários anos. A seleção lexical de Rosa ("bem vista") indica que a avaliação que faz das escolhas linguísticas da escola é positiva.

Destarte, percebemos como a governamentalidade foucaultiana da qual falamos se expressa no nível individual, da conduta e governo de si mesmo, já que a instituição elegeu a oferta e curso obrigatório de inglês e espanhol para os alunos do Ensino Médio. Em contrapartida, fica claro que o governo do Estado exerce, igualmente, uma força imperativa sobre as políticas linguísticas da escola. Isso porque essa instituição faz parte de uma "conjuntura" em que um dos reguladores do que se oferece aos alunos em termos de línguas estrangeiras é o próprio governo do Estado.

Ainda assim, o poder local e o nacional são forças díspares, sendo a mais forte delas, neste contexto, esta última. Isso ocorre porque a LDB de 1996/2010, ainda em vigor, determina que é obrigatória a oferta de uma língua estrangeira na grade curricular regular do Ensino Médio e facultativa a oferta de uma segunda língua estrangeira moderna, de acordo com as possibilidades da escola. Bem, se, por um lado, oferecer uma língua estrangeira moderna é obrigatório de acordo com as leis do Estado (LDB, 1996/2010), por outro lado, o fato de a escola poder oferecer mais uma língua estrangeira (neste caso, o espanhol), obrigando os alunos a cursá-la, também tem como base a permissão (ou orientação) do governo do Estado para que essa prática se efetive. Seguindo Tollefson (2006), podemos dizer que, nesse caso, as relações de poder manifestam-se nas decisões político-linguísticas.

Mas, já que a participante relata que a língua espanhola não era obrigatória por lei quando da decisão da escola por ofertá-la no Ensino Médio, o ensejo permitiu questioná-la sobre se, então, a Lei 11161/2005 influenciou, em alguma medida, a política linguística na instituição. Rosa respondeu:

Aí nós justificamos uma vaga pra um professor efetivo. Né? Influenciou nesse sentido (...) o quê a gente conseguiu pra justificar a entrada de um professor de espanhol foi exatamente isso, 
né, o cumprimento de uma lei que ainda estava... (...) apenas um aconselhamento do governo, né, até que a... que se faça realmente a obrigatoriedade. (Excerto de entrevista - 17.01.2013)

Temos, então, a influência de tal Lei apenas no quadro efetivo de professores da escola, o que significa que, no que concerne à oferta de línguas estrangeiras, não houve alteração entre a situação prévia e a posterior à implantação da Lei 11161/2005. No entanto, na expressão da participante está implícita a relevância da legislação para assegurar a oferta da língua espanhola. Estando amparada legalmente, a instituição não precisaria desfazer-se do professor não efetivo de língua espanhola nem, consequentemente, temer a uma mudança forçada na postura adotada: a oferta regular permanente das duas línguas (inglês e espanhol) na escola.

Também é de nosso interesse saber o porquê de o inglês e o espanhol serem as línguas ofertadas na instituição. Como dissemos na descrição da escola, esta se encontra em uma zona interiorana do Rio Grande do Sul, colonizada essencialmente por italianos, dos quais a língua é uma herança permanente no contato interpessoal diário e existe como marca identitária daqueles que ali habitam. Nos nomes de muitos estabelecimentos da cidade, a língua italiana se faz presente (Figuras 3, 4, 5 e 6).

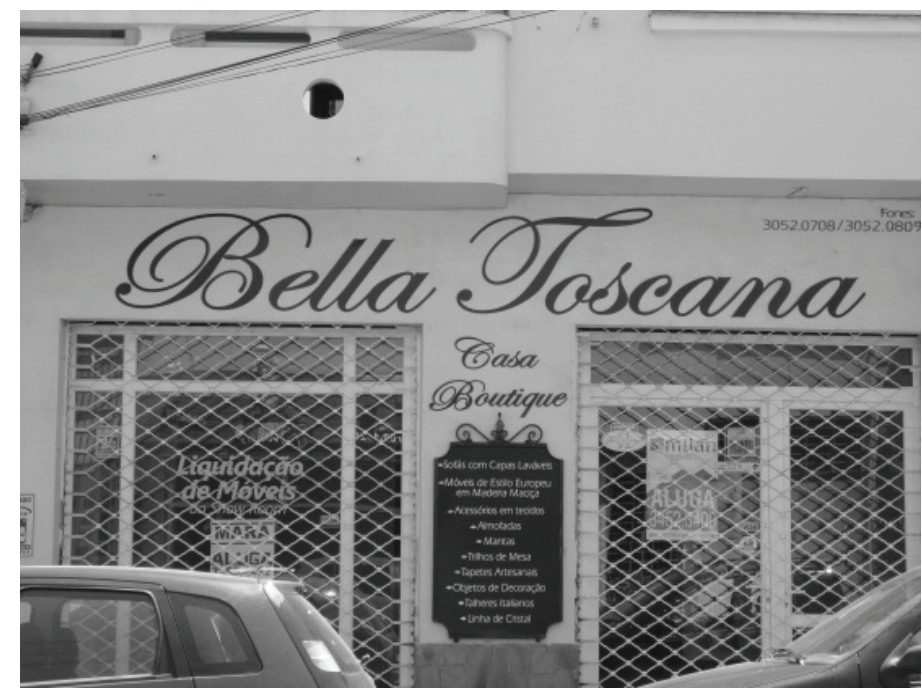

Figura 3. Bella Toscana - Artigos para o Lar 


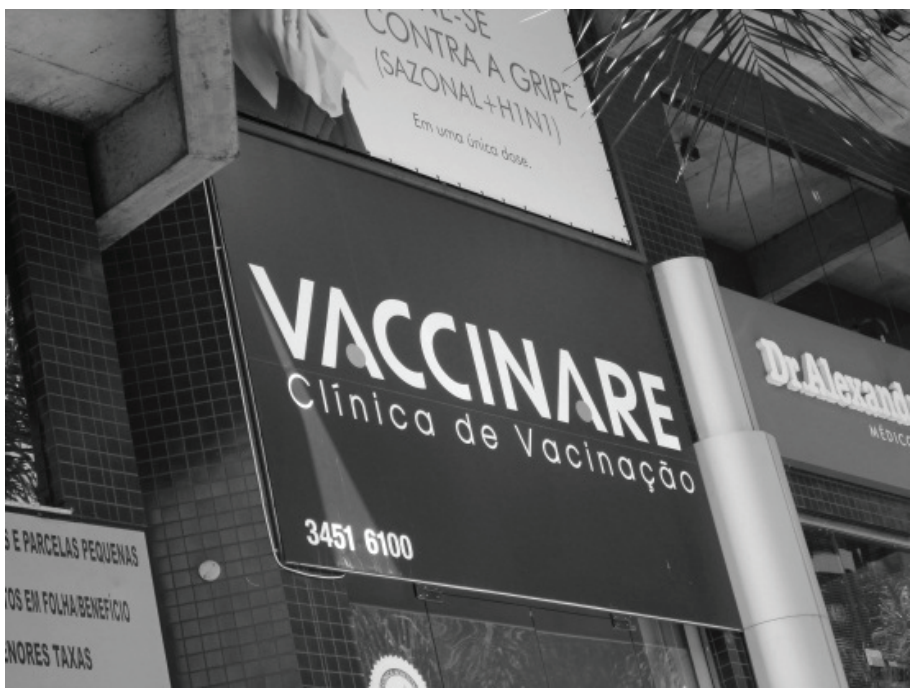

Figura 4. Vaccinare - Clínica de Vacinação

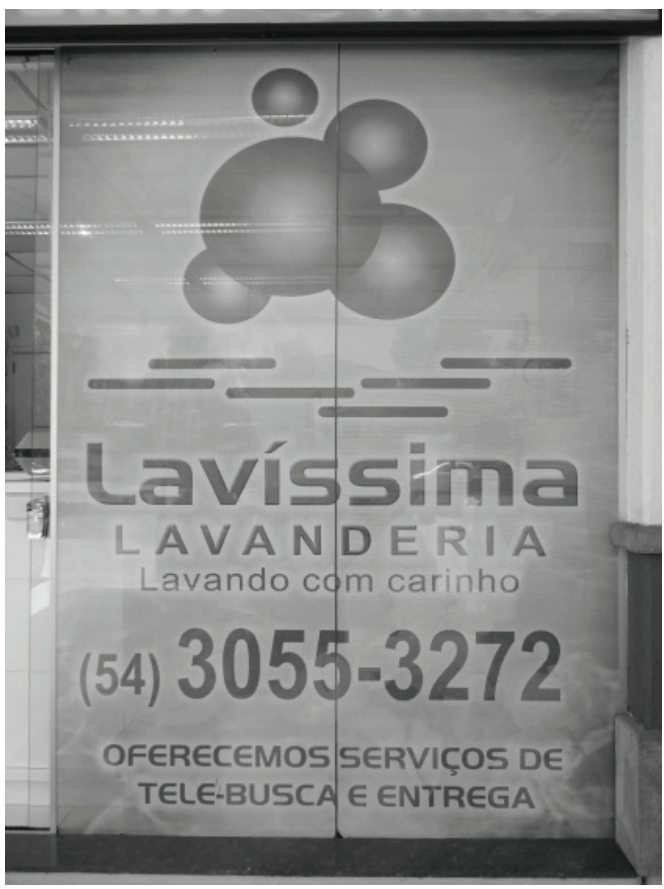

Figura 5. Lavíssima - Lavanderia 


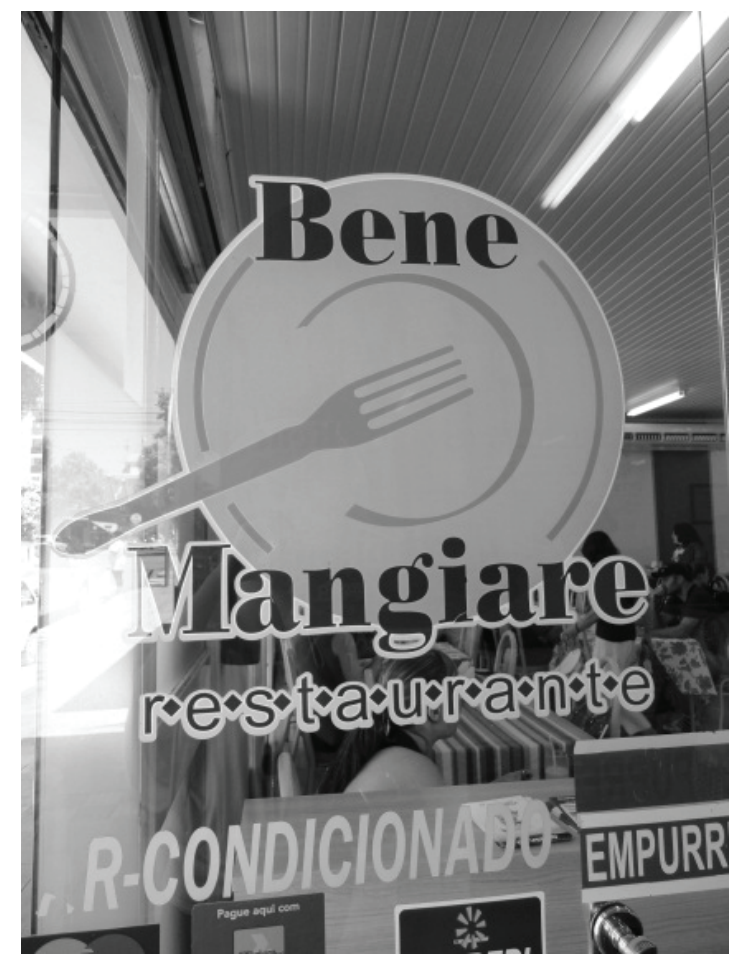

Figura 6. Bene Mangiare - Restaurante

Nesse ínterim, e defrontando-nos com os ideais estabelecidos em documentos reguladores das ofertas de línguas estrangeiras em âmbito nacional, tais como os PCN-EM (1999/2000), vejamos o que se preconiza nas bases educacionais do Estado a respeito do tema:

Por outro lado, como a lei prevê a inclusão de uma segunda Língua Estrangeira Moderna em caráter optativo, parece conveniente vincular tal oferta também aos interesses da comunidade. Dessa forma, é provável que em determinadas áreas do Rio Grande do Sul, por exemplo, seja muito mais significativo o ensino do italiano, em função das colônias italianas presentes no local, do que oferecer cursos de francês; em regiões onde a presença alemã é mais marcante, provavelmente o ensino dessa língua adquira um significado mais relevante do que o japonês. É preciso observar a realidade local, conbecer a bistória da região e os interesses da clientela a quem se destina esse ensino. Em suma: é preciso, agora, não mais adequar o aluno às características da escola, mas, sim, a escola às necessidades da comunidade (PCN-EM, 1999/2000, p. 27; grifo meu).

Como podemos observar, nos PCN-EM (1999/2000) enfatiza-se a relevância das línguas da região, de importância para a comunidade local, na composição do currículo escolar. Esse documento é, assim como a lei, uma representação da 
governamentalidade estatal, mas, como percebemos, na conduta singular da escola, suas indicações não são atendidas. Isso demonstra como exercício do poder é transitório, tal como propõe o conceito de Foucault (1979/2009), já que agora é a conduta da escola que se sobressai à do Estado.

Quando buscamos saber, então, sobre a possibilidade de outra língua ser oferecida na escola, além das que conformam o currículo do Ensino Médio, a ex-coordenadora diz: "Nunca se cogitou, né? (...) nem se pensou numa outra possibilidade, não desprezando as outras línguas (...)" (Excerto de entrevista - 17.01.2013). Essas palavras são relevantes e bastariam para entender o motivo pelo qual não há espaço para outra língua estrangeira na escola, além do espanhol e do inglês. Nunca houve, segundo Rosa, uma discussão sobre o tema.

Contudo, seguimos nos questionando quanto ao fato de o inglês e o espanhol serem as línguas escolhidas para permanecer na grade curricular de todos os cursos de nível Médio. Vejamos dois momentos em que a participante se expressa em relação a essa escolha: "Mas na minha época já tava bem tranquilo, né, trabalhar com a, com a língua espanhola, assim... bem definido". (Excerto de entrevista 17.01.2013). E, referindo-se ao inglês, diz: "(...) bem tranquilo na escola. Não se percebia nenhuma situação de preferência. Nem se discutia o tema. Era algo muito tranquilo." (Excerto de entrevista - 17.01.2013).

Chama a atenção o uso repetido da palavra 'tranquilo'. Uma vez mais, recorrendo ao dicionário Houaiss (2001), encontramos entre as entradas léxicas, uma que a define como aquilo "que não é passível de dúvida; seguro". Isso nos leva a crer que a decisão por aquelas duas línguas não era motivo de receio, não gerava perturbação. A segurança frente às línguas escolhidas parece-nos calcada fortemente na ideologia linguística do mundo capitalista global e, além disso, uma prática discursiva já operante (PENNYCOOK, 2006).

Diante dos relatos de Rosa, conseguimos depreender que: a) as línguas estrangeiras ofertadas na escola são o inglês e o espanhol e essa escolha não instiga qualquer discussão; b) há decisões político-linguísticas em âmbito local, porém sempre delimitadas pelas regulamentações do governo Estatal (LDB, 1996/2010); c) a Lei 11161/2005 não alterou a oferta de línguas estrangeiras na escola, visto que a língua espanhola já era oferecida (e exigida) antes mesmo da implantação dessa Lei; d) a língua da comunidade social (o italiano) (PCN-EM, 2000), ou qualquer outra língua estrangeira diferente das duas que compõem a grade curricular, não desperta o interesse da escola para ser formalmente ensinada; e) as línguas inglesa e espanhola são consideradas importantes. 
Dando continuidade aos nossos questionamentos, buscamos conhecer as perspectivas dos alunos-participantes com relação a esses mesmos temas.

\subsection{Por causa que é da grade curricular, aí tu se obriga a fazer. - a perspectiva dos alunos frente à oferta de línguas estrangeiras na escola}

Vítor, aluno do curso técnico em Agropecuária (AP), leva em consideração, primeiramente, a língua que aprendeu em casa, o alemão. $\mathrm{O}$ participante começa nossa conversa dizendo o quanto essa língua é relevante para ele pelo fato de que é a língua que todos falam na sua casa, mas que ele, ao contrário, não consegue se expressar oralmente nela, apenas a compreende. Aproveitamos o ensejo para perguntar qual língua ele estudaria formalmente se pudesse fazê-lo na escola. Vítor diz:

\footnotetext{
Ah, eu escolheria ser fluente em alemão, porque é a língua que eu me identifico mais. Aí, todo mundo fala alemão lá e eu não consigo, eu não consigo conversar com eles. Só entendo, mas aí eu tenho que responder em português. Aí, pra conseguir lá conversar com o meu vô, com o meu tio... (Excerto de entrevista - 07.01.2013)
}

Como podemos observar, um dos desejos linguísticos do participante é poder desenvolver a língua que aprendeu em casa, se tivesse essa oportunidade na escola. Para ele, o alemão está ligado às relações intrafamiliares e, portanto, existe um vínculo afetivo com essa língua. Mas, como sabemos, esse desejo não é atendido. Mesmo assim, pensamos que se a língua alemã fosse oferecida na escola, provavelmente não seria a mesma variedade usada por seus familiares devido a questões, também de ordem política, como a padronização e internacionalização ${ }^{18}$ linguísticas, por exemplo.

É interessante notar que Alice, aluna do curso técnico em Informática para a Internet (II), apresenta uma opinião semelhante à de Vítor. Após relatar que gostaria de ir além daquilo que a escola oferece como opção de estudo de línguas estrangeiras, a participante revela seus anseios: "Eu quero fazer curso de espanhol e italiano, sabe? Ficar mais fluente nessas duas. É que minha mãe mora na Itália, daí seria melhor pra mim, né?" (Excerto de entrevista - 04.01.2013).

Essa declaração traz consigo pelo menos três aspectos relevantes. Primeiro, não podemos desconsiderar o fato de que a pesquisadora que fazia a entrevista foi

\footnotetext{
18 O termo 'padronização' é tomado no sentido de língua padrão, concebida como aquela que se desenvolve como norma e sobrepõe-se às diferenças regionais ou sociais (HORNBERGER, 2006). Já o termo 'internacionalização' refere-se à preferência pela propagação dessa língua em nível mundial.
} 
também professora de espanhol de Alice durante dois anos e que é com ela que essa aluna está dialogando. Assim, sua vontade de estudar espanhol depois de terminados os estudos escolares pode ser legítima, mas existe a possibilidade de que isso tenha sido dito pela posição de ex-professora que a entrevistadora exercia ali. Segundo, análogo ao caso do Vítor, a língua italiana parece ter um vínculo afetivo (e, também, instrumental), já que é a atual língua em uso de sua mãe (e, provavelmente, de alguns de seus familiares, devido à descendência italiana de Alice). Terceiro, e mais importante para nossos objetivos, outra vez percebemos que existe o desejo de estudar uma língua estrangeira diferente daquelas oferecidas pela instituição.

Contudo, devemos considerar diferentes hipóteses que podem intervir na decisão da escola em oferecer inglês e espanhol como línguas estrangeiras. Relacionando a situação ao conceito foucaultiano, podemos supor (ainda que nada tenha sido dito a respeito $\left.{ }^{19}\right)$, que, na prática, a escolha é uma resposta a intervenções governamentais do Estado, como, por exemplo, a necessidade de oferecer aos alunos as línguas exigidas em um dos maiores processos seletivos de ingresso ao Ensino Superior no Brasil, como é o caso do ENEM.

Quando Vítor é questionado sobre a possibilidade de escolher apenas uma das duas línguas que a escola disponibiliza, o participante relata: "Se eu pudesse escolher entre as duas, eu deixaria de estudar espanhol e estudaria mais o inglês. Porque o inglês é mais cobrado atualmente. (...) eu entendo melhor o inglês porque o alemão é muito parecido com o inglês." (Excerto de entrevista - 07.01.2013). Isso indica que, para Vítor, a língua almejada serve também como suporte para a aprendizagem de outra língua, a qual considera secundariamente importante: o inglês.

Nesse trecho da entrevista percebemos o caráter instrumental atribuído à língua inglesa, mas, ainda assim, a língua do desejo - a alemã - poderia ajudá-lo a desenvolver aquela língua. Dessa forma, estudar alemão continua sendo relevante para ele. Contudo, o participante parece ter bem clara sua situação frente às imposições da instituição. Quando sondamos sobre a razão que o levou a estudar espanhol e inglês na escola, ele respondeu: "Por obrigação. Por causa que é da grade curricular, aí tu se obriga a fazer." (Excerto de entrevista - 07.01.2013). Alice tem o mesmo posicionamento. Ao enunciar "O que tu fez, até agora, tu fez, na verdade, porque...", referindo-nos ao estudo de inglês e espanhol na escola, ela logo completou: "Porque tinha que fazer, no caso." (Excerto de entrevista - 04.01.2013).

Nesse contexto, durante a entrevista com Vítor, buscamos saber como ele acredita que deveria ser, então, a exigência da escola no que se refere às línguas

19 Lembramos, aqui, da ideia de ideologia tácita apontada por Kroskrity (2004), apresentada anteriormente neste texto, de uma conduta quase irreflexiva, a qual, na hipótese que levantamos, pode ter conduzido os gestores da escola a cumprir com as demandas geradas pelo Estado. 
estrangeiras oferecidas. O participante diz: "(..) mas eu ainda acho que tinha que ser opcional (...) escolher uma das duas línguas, ou, se tu quer fazer as duas, daí é escolha tua. Mas eu acho que tinha que ser opcional porque tu ser obrigado não vai adiantar. Se tu não quer, não adianta. (Excerto de entrevista - 07.01.2013).

Além da alteração sugerida, o participante mostra-se descontente com a carga horária destinada às línguas estrangeiras ao longo do Ensino Médio, para a qual também propõe mudanças:

(...) eu acho que não é adequado o jeito que é ensinado, aqui, as línguas. Sei lá. Talvez até por causa do pouco tempo. Mas, não... não me agrada (...) A língua estrangeira, ela tinha que ter até mais, mais períodos do que o comum (...) é muito pouco tu ter dois períodos durante dois anos, que tu não vai aprender quase nada. Nem o básico tu vai conseguir... (Excerto de entrevista - 07.01.2013)

Como se vê, o tempo disponibilizado para a aprendizagem de inglês e espanhol na escola não parece suficiente, segundo o participante. Com a carga horária de dois períodos semanais durante dois anos, segundo ele, não é possível aprender "nem o básico". Ademais, a língua inglesa mereceria mais destaque, visto que é fundamental para os estudos da área técnica em que está se formando:

O inglês tinha que ser mais cobrado, mais intensivo, de forma que tu aprenda mesmo. Porque eu, nesses trabalhos [da área técnica], eu percebi que eu não tinha capacidade de traduzir, hã, os artigos. Aí tu tinha que ir no tradutor, usar o computador, porque tu não consegue... é muito pouco... (Excerto de entrevista - 07.01.2013)

Alice, da mesma forma, considera o ensino de inglês essencial para a sua área técnica, diferentemente do espanhol. Sobre a oferta de espanhol para os conhecimentos específicos do curso, ela explicita: "(...) na minha área não tem muita coisa em espanhol, daí, não precisa tanto, voltado ao curso." (Excerto de entrevista - 04.01.2013). Em outro momento da entrevista, a respeito do mesmo tema, diz: "Ah, espanhol não. Área técnica não tem. Mas é que tudo é feito... os códigos, tudo é feito em inglês, né? Mas, [espanhol] é bom pra falar com cliente e se comunicar, né? Mas não tem a ver muito com o curso." (Excerto de entrevista - 04.01.2013).

Após analisar todos esses excertos, observamos a seguinte realidade, para os alunos participantes desta pesquisa, no que concerne à oferta de línguas estrangeiras para o Ensino Médio Integrado na escola: a) Os alunos, em primeira instância, obedecem à imposição curricular quanto às línguas estrangeiras cursadas, pois nenhuma das duas oferecidas pela escola é a primeira opção, em termos de desejo de aprendizagem, por parte dos participantes; b) Ambos os participantes gostariam que a escola oferecesse outras línguas estrangeiras (em especial aquelas com que 
têm um vínculo afetivo) além das que fazem parte da grade curricular; c) Segundo um dos participantes, seria necessário que houvesse mais horas-aula para as disciplinas de língua estrangeira e, além disso, deveria ser de livre escolha a língua a ser cursada pelos alunos; d) Os participantes declaram, consonantemente, que a língua inglesa é fundamental para a sua área técnica.

Neste instante, retomamos nossa pergunta de pesquisa: há indícios de que a visão ideológica dos alunos está em consonância com a política linguística da escola para as línguas estrangeiras no Ensino Médio? Comecemos por considerar que, na escola investigada, os alunos do Ensino Médio têm de cursar língua inglesa e língua espanhola. Vimos que, para Rosa, essas línguas são importantes na sociedade moderna. Tal perspectiva parece alinhada à ideologia representativa dos discursos hegemônicos, originária de Estados política e economicamente poderosos. Para ela, é inquestionável que aquelas sejam as línguas a serem ofertadas na escola. O discurso de Rosa está, portanto, em consonância com aquele que circula na sociedade. Nos termos de Pennycook (2006), é uma expressão da governamentalidade linguística.

Em contrapartida, e sem desconsiderar a importância de qualquer uma dessas línguas, os alunos participantes aspiram cursar línguas estrangeiras que não são ofertadas na instituição. Portanto, percebemos que seus anseios não são tomados pela escola como um ponto de partida para a escolha das línguas estrangeiras que compõem a grade curricular.

Ao contrário do que sugerem os PCN-EM (1999/2000), continua havendo uma adequação do aluno à escola, e não da escola aos seus alunos. Devemos perceber que as línguas almejadas por Alice e Vítor (italiano e alemão) são as línguas de imigração das comunidades da região geográfica em que está localizada a escola e, também por fatores imigratórios, a língua de ascendência de seus progenitores. Mas essa realidade, ou é invisível, ou é ocultada pelos agentes escolares que ocupam a posição de tomar decisões a respeito das línguas.

Isso exemplifica como a governamentalidade aparece partindo das instâncias maiores (em termos de poder político) em direção às instâncias menores, embora estas possuam auto-governo. Subjetivamente, a conduta dos alunos é guiada por anseios linguísticos que não são atendidos, tendo em vista a força superior dos responsáveis pelas escolhas institucionais: os gestores. E, ainda mais, da força do governo do Estado, em várias de suas medidas e regulamentações, sobre os gestores e a instituição. 


\section{CONSIDERAÇÕES FINAIS}

A crença no valor das línguas inglesa e espanhola está fortemente enraizada no discurso da ex-coordenadora e visível nos documentos da instituição, estabelecendo um quadro de tranquilidade e segurança diante da escolha tomada, que não produziu (e nem produz) debates acerca do tema. Como propõe Kroskrity (2004), trata-se de uma ideologia que representa a concepção de um grupo - do governo do Estado e, por conseguinte, da sociedade brasileira, em geral - que é (re)produzida na escola. Assim, a governamentalidade da escola prevalece sobre a dos alunos Alice e Vítor, já que aquela não lhes concede o direito de auto-governo para escolher aprender uma língua estrangeira que é significativa para eles.

O único (e mínimo) indício de que alguma das concepções linguísticas dos alunos começa a ser atendida radica no fato de que o inglês parece estar sendo entendido como verdadeiramente indispensável em função dos conteúdos técnicos estudados, já que houve uma mudança de 160 para 200 horas de aula no curso de AP, segundo PPC de 2011. No entanto, as horas dedicadas a essa disciplina parecem ser insuficientes para cumprir com as expectativas dos alunos.

Seria necessário, por conseguinte, estudar a situação da oferta de línguas estrangeiras na escola, fazendo-se uma série de pesquisas a fim de trazer contribuições (como esperamos ter dado o pontapé inicial aqui) e propor uma política linguística efetiva, que esteja atenta à realidade local dos alunos, às suas necessidades e desejos pessoais e acadêmicos, e não apenas reproduzindo as ideologias linguísticas dominantes na sociedade brasileira.

Um dos caminhos possíveis para isso seria, em primeira instância, realizar um estudo sobre as línguas que circulam na sociedade, descobrir as funções que cumprem naquele contexto e de que modo relacionam-se com a vida dos alunos. Além disso, seria importante fazer um levantamento sobre quais línguas os alunos da escola gostariam de aprender formalmente nesse ambiente e por quê. Com todos esses dados em mãos, os professores de línguas estrangeiras poderiam analisá-los, discuti-los e, posteriormente, promover debates com seus alunos para realocar (se fosse o caso) a posição das línguas estrangeiras oferecidas na escola, segundo a preferência desse público.

Como ação paralela, os professores levariam aos gestores da instituição as perspectivas apontadas pelos alunos, propondo uma reflexão teórica para, depois, interferir nas ações da escola sobre a oferta de línguas estrangeiras. A partir disso, seria possível elaborar um projeto de política de oferta dessas línguas na escola. A 
posta em prática desse projeto levaria a estabelecer algumas diretrizes, mas, é claro, essas deveriam ser periodicamente revisadas e atualizadas.

\section{REFERÊNCIAS BIBLIOGRÁFICAS}

AMOS, K. (2010). Governança e governamentalidade: relação e relevância de dois conceitos científico-sociais proeminentes na educação comparada. Educação e Pesquisa: São Paulo, vol. 36, n. especial, p. 23-38.

BLOMMAERT, J. (2006). Language Policy and National Identity. In: Ricento, T. (org.) An introduction to Language Policy: theory and method. Malden, MA, USA: Blackwell Publishing.

BRASIL. Ministério da Educação. (1999/2000). Secretaria de Educação Média e Tecnológica. Parâmetros Curriculares Nacionais: Ensino Médio. Linguagens, Códigos e suas Tecnologias. Brasília: Ministério da Educação. Disponível em: < http://portal.mec.gov. br/seb/arquivos/pdf/14_24.pdf $>$ Acesso em: 06 dez. 2012.

BRASIL. LEI DE DIRETRIZES E BASES DA EDUCAÇÃO NACIONAL. (1996/2010) 5 ed. Brasília: Edições Câmara.

BRASIL. Lei $N^{0}$ 11.161, de 05 de agosto de 2005. Disponível em: < http://www.camara. gov.br> Acesso em: 06 dez. 2012.

CANAGARAJAH, S. (2006). Ethnographic Methods in Language Policy. In: Ricento, T. (org.) An introduction to Language Policy: theory and method. Malden, MA, USA: Blackwell Publishing.

FOUCAULT, M. (1979/2009). Governamentalidade. In: Foucault, M. Microfísica do poder, trad. Roberto Machado. Rio de Janeiro: Edições Graal.

GONZÁLEZ, N. M. (2010). Iniciativas para a implantação do espanhol: a distância entre o discurso e a prática. In: BRASIL. Ministério da Educação (MEC). Secretaria da Educação Básica. Espanhol: Ensino Médio. Brasília, 292 p. Barros, C. S. de; Costa, E. G. de M. (Coords.) Coleção Explorando o Ensino. Cap. 2.

HORNBERGER, N. (2006). Frameworks and models in Language Policy and Planning. In: Ricento, T. (org.) An introduction to Language Policy: theory and method. Malden, MA, USA: Blackwell Publishing.

HOUAISS Dicionário eletrônico da língua portuguesa 1.0 (2001) Editora Objetiva.

KAPLAN, R. B; BALDAUF JR., R. B. (1997). Language Planning: from practice to theory. Bristol, USA: Multiligual Matters.

KROSKRITY, P. (2004). Language Ideology. In: Duranti, A. (ed.) A companion to linguistic anthropology. Malden, MA, USA: Blackwell Publishing.

LUDWIG, A. C. W. (2009). Fundamentos e prática de metodologia científica. Petrópolis, RJ: Vozes.

MACHADO, R. (2009). Por uma genealogia do poder. In: Foucault, M. Microfísica do poder, trad. Roberto Machado. Rio de Janeiro: Edições Graal. 
MATTOS, C. L. G. (2001). A abordagem etnográfica na investigação científica. Disponível em: < http://people.ufpr.br/ marizalmeida/celem05/abord etnogr invest cient.

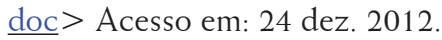

MCCARTY, T. (ed.) (2011) Ethnograpby and Language Policy. New York: Routledge.

MENKEN, K; GARCÍA, O. (eds.) (2010). Negotiating Language Policies in Schools: Educators as Policymakers. New York: Routledge.

PENNYCOOK, A. (2006). Postmodernism in Language Policy. In: Ricento, T. (org.) An introduction to Language Policy: theory and method. Malden, MA, USA: Blackwell Publishing.

RICENTO, T. (2006). Language Policy: Theory and Practice - An Introduction. In: Ricento, T. (org.) An introduction to Language Policy: theory and method. Malden, MA, USA: Blackwell Publishing.

RODRIGUES, F. S. C. (2010). Leis e línguas: o lugar do espanhol na escola brasileira. In: BRASIL. Ministério da Educação (MEC). Secretaria da Educação Básica. Espanhol: Ensino Médio. Brasília, 292 p. Barros, C. S. de; Costa, E. G. de M. (Coords.) Coleção Explorando o Ensino. Cap. 1.

ROSSI, C. (2005). Lula na Espanha. Brasil quer trocar dívida por professor. São Paulo. Folha de São Paulo. Disponível em < http://www1.folha.uol.com.br/fsp/cotidian/ ff1510200522.htm $>$ Acesso em: 20 jan. 2013.

TOLlEFSON, J. (2006). Critical Theory in Language Policy. In: Ricento, T. (org.) An introduction to Language Policy: theory and method. Malden, MA, USA: Blackwell Publishing.

VEIGA-NETO, A; LOPES, M. C. (2007). Inclusão e governamentalidade. Educ. Soc.: Campinas, v. 28, n. 100 - Especial, p. 947-963.

WOOLARD, K. (1992) Language Ideology: issues and approaches. Quarterly Publication of the International Pragmatics Association. vol. 2, n. 3.

Recebido: 09/07/2013

Aceito: 07/04/2014 